\title{
EL III CONGRESO INTERNACIONAL DE MUSICOLOGÍA EN BARCELONA 1936, A PARTIR DE LA DOCUMENTACIÓN GUARDADA EN EL FONDO HIGINI ANGLÈS DE LA BIBLIOTECA DE CATALUNYA
}

\author{
THE ' $3^{\text {rd }}$ INTERNATIONAL CONFERENCE OF MUSICOLOGY' \\ (BARCELONA, 1936), FROM THE DOCUMENTATION PRESERVED IN \\ THE 'FONS HIGINI ANGLÉS' OF THE BIBLIOTECA DE CATALUNYA
}

César Calmell i Piguillem

Universitat Autònoma de Barcelona

\begin{abstract}
Resumen
Apenas tres meses antes de que se iniciara la Guerra Civil se celebraron simultáneamente en Barcelona el III Congreso Internacional de Musicología y el XIV Festival Internacional para la Música Contemporánea, dos acontecimientos musicales que fueron exponente del proceso imparable de normalización y europeización en que se hallaba inmersa la actividad y la cultura musical de aquella ciudad desde comienzos del siglo XX. Centrándose en el Congreso, y el protagonismo que en él tuvo su secretario mosén Higini Anglès, en este artículo se ha investigado su génesis, la estructura y organización de aquellas jornadas, y su reconstrucción en número de comunicaciones leídas y conservadas, a partir de la documentación que sobre dicho Congreso Internacional guarda la Biblioteca de Catalunya en su Fondo Personal Higini Anglès..
\end{abstract}

\section{Palabras clave}

Higini Anglès; Edward J. Dent; Robert Gerhard; Joan Lamote de Grignon; Pau Casals; Adolfo Salazar; Enrique FernándezArbós; Joan Llongueras; Manuel de Falla; Joaquín Turina; Baltasar Samper; José Subirà; Joan Salvat; Dom Joseph Gajard; Johannes Wolff; Heinrich Besseler; Manfred Bukofzer; Alfred Einstein; Curt Sachs, Egon Wellesz, III Congreso Internacional de Musicología, Asociación Internacional de Musicología (SIM); XIV Festival Internacional de Música Contemporánea; Asociación Internacional para la Música Contemporánea (SIMC); Biblioteca de Catalunya; Institut d'Estudis Catalans; canto gregoriano; Solesmes; conciertos históricos; folklore; música antigua.

\begin{abstract}
Barely three months before the Civil War began, Barcelona was the meeting point of o the Third International Congress of Musicology and the XIV International Festival for Contemporary Music, two events celebrated simultaneously that were, both of them, exponent of the irrepressible process of modernization and Europeanization in which the musical activity and culture of that city was immersed since the early twentieth century. Focusing on the Congress, and on the leadership that Higini Anglès had in it as its General Secretary, in this article we have investigated its genesis, structure and organization of the meeting, and its reconstruction in number of communications read and preserved from the documentation about this International Congress kept at the Biblioteca de Catalunya, as Higini Anglès's Personal Collection.
\end{abstract}

\section{Key words}

Higini Anglès; Edward J. Dent; Robert Gerhard; Joan Lamote de Grignon; Pau Casals; Adolfo Salazar; Enrique FernándezArbós; Joan Llongueras; Manuel de Falla; Joaquín Turina; Baltasar Samper; José Subirà; Joan Salvat; Dom Joseph Gajard; Johannes Wolff; Heinrich Besseler; Manfred Bukofzer; Alfred Einstein; Curt Sachs; Egon Wellesz, III International Congress of Musicology; International Musicological Society (IMS); XIV International Festival for Contemporary Music; International Society for Contemporary Music (ISCM); Catalonia National Library; Institute for Catalan Studies; Gregorian chant; Solesmes; historical concerts; folklore; ancient music. 


\section{Festival y Congreso en Barcelona}

Durante una semana, del sábado 18 al siguiente sábado 25.04.1936, es decir tres meses antes del comienzo de la Guerra civil española, tuvo lugar en Barcelona la celebración simultánea del XIV Festival de la Sociedad Internacional para la Música Contemporánea y del III Congreso de la Sociedad Internacional de Musicología, motivo por el que la Ciudad Condal se convirtió durante aquel lapso breve de tiempo en centro de atracción internacional de la actividad musical, ya que si el Festival exponía una muestra de la creación musical reciente -eso sí, sesgada hasta cierto punto por la influencia dominante de los compositores formados en el internacionalismo de la Escuela vienesa-, por otro lado, el Congreso constituyó el primer ensayo llevado a cabo en tierras hispanas de sistematización expositiva de los conocimientos operados en los distintos ámbitos disciplinares de la musicología contemporánea. Y además, y esto era una novedad, la convergencia temporal de ambos eventos en una misma ciudad de acogida sentaba las bases para el diálogo fructífero entre artistas e investigadores en el ámbito musical.

Una serie de hechos fueron los determinantes para que Festival y Congreso coincidieran en Barcelona: en primer lugar y fundamentalmente, la gestión preparatoria desplegada en el seno de las dos instituciones internacionales, la ISCM (International Society for Contemporary Music) y la IMS (International Musicological Society) por parte, respectivamente, de dos de sus distinguidos miembros catalanes -el compositor Robert Gerhard y mosén Higini Anglès- para obtener la nominación barcelonesa, y una vez conseguida ésta, el trabajo de estas dos misma personas en la organización de las sesiones tanto musicales como académicas que debían desarrollarse a lo largo de aquella semana intensa en actividades.

En segundo lugar, se daba la circunstancia decisiva de que desde 1931 el musicólogo Edward Joseph Dent, -presidente desde su creación en 1922 de la ISCM (Sociedad Internacional para la Música Contemporánea, (SIMC) en castellano) -, había asumido igualmente, tras la muerte de Peter Wagner, la presidencia de la IMS (Sociedad Internacional de Musicología, (SIM) en castellano) con sede en Basilea, por lo que ambas asociaciones quedaban desde aquel momento estrechamente vinculadas en la figura de su máximo responsable. De esta manera, y puesto que la convocatoria de los festivales promovidos por la SIMC eran anuales y se celebraban cada año en una ciudad distinta, mientras que los congresos a cargo de la SIM eran convocados cada tres años, el proyecto de Dent fue el de hacer coincidir trianualmente festival y congreso en el mismo lugar elegido para albergar al primero. Precedente al de Barcelona 1936, fue el encuentro en Liège (1930) ya que el de Cambridge (1933) reunió sólo a los musicólogos aunque fuera en esta Conferencia dónde la Asamblea de SIM allí convocada aprobó formalmente la candidatura barcelonesa de 1936 presentada por Higini Anglès, nominación que, aunque ansiada, despertó al principio, una vez ya obtenida, serias dudas y escepticismo en el ánimo de su máximo impulsor ante el temor de no ser capaz, en un país falto de tradición en los estudios de musicología como el nuestro, de poder asumir aquel reto. Higini Anglès todavía recordaba aquella desconfianza inicial en su alocución de despedida a los numerosos visitantes extranjeros presentes durante el acto de clausura -el sábado, 25 de abril- del III Congreso de la SIM en el Institut d'Estudis Catalans:

«Sincèremet nous avions craigné que la musicologie hispanique, si jeune dans notre pays ne serait digne de vôtres œuvres scientifiques et de bien accueillir un Congrès de la SIM» ${ }^{1}$

Si la delegación presente en Cambridge, continuaba Anglès, terminó por aceptar la propuesta fue impelida por el ejemplo de aquellos grandes maestros, y el más ilustre de ellos quizás fuera Felip Pedrell, que con su valiosa obra establecía los fundamentos de la musicología en nuestro país.

En tercer lugar, fue crucial el apoyo incondicional tanto de amplios sectores e instituciones musicales y culturales catalanas como del Gobierno autonómico y el de la Corporación municipal barcelonesa que precisamente vieron en la promoción de estos dos eventos una oportunidad para convertir la ciudad Condal en centro de atención cultural internacional en un momento delicado como en el que se vivía como consecuencia de los graves sucesos del 06.10.1934 que habían impuesto el estado de guerra en Catalunya -estado que se prolongó hasta finales de abril de 1935- y la suspensión de las garantías democráticas. En este ambiente de inestabilidad política, el Consell de Cultura de la Generalitat $^{2}$ hace suya la primera propuesta formal presentada por la Subponencia de Música y Ponencia de Fondos, Bibliotecas y Bellas Artes en conexión conjunta con la Sección Catalana del Festival de la SIMC y la Delegación Española del Congreso de la SIM, y eleva a Presidencia la solicitud oficial de una subvención para la organización y realización en

1 ANGLES, (Abril, 1936), Discurs de cloenda, [10 hojas en medio folio, autógrafas], Documentació SIM, Fons Higini Anglès Biblioteca de Catalunya $(\boldsymbol{E}-B b c)$.

2 Acta de la reunión de Consell de Cultura del día 02.03.1935, presidida por su Secretario, el Sr. Alexandre Galí, Documentació Congrés, Fons Higini Anglès Biblioteca de Catalunya $(\boldsymbol{E}-B b c)$. 
Barcelona de ambos acontecimientos previa presentación de un presupuesto general de 250.000 pts: 143.000 para hacer frente a los conciertos del Festival, y 107.000 para cubrir los gastos de los conciertos de "música antiga" (conciertos históricos) que debían celebrarse como complemento público y participativo de las sesiones estrictamente académicas del Congreso de musicología. En la primera de las partidas, se incluía además un apartado correspondiente a la puesta en funcionamiento de una secretaría con su capítulo de retribuciones de personal pertinente, publicación de materiales y de propaganda y alojamiento de los miembros del comité ejecutivo tanto de la SIMC como de la SIM durante los días de celebración del Festival y del Congreso.

\section{Génesis del Congreso de musicología}

Evidentemente, en la solicitud de subvención a la Generalitat -que poco después había de hacerse igualmente extensiva al Ayuntamiento de Barcelona- sólo se pedía un porcentaje más bien reducido del presupuesto general, ya que a través de otro documento ${ }^{3}$ sabemos que la cuantía solicitada en partes iguales a ambas administraciones catalanas para 1936 ascendía a un total 68.000 pts, de las cuales en el ejercicio del año anterior Generalitat y Ayuntamiento ya habían hecho efectivas a los organizadores 20.000 pts. Del resto hasta cubrir las 250.000 pesetas presupuestadas en el proyecto, quedaba claro que debía hacerse cargo el Gobierno español, pero esta fue una presuposición errónea en lo concerniente al Congreso, ya que el Ministerio de Instrucción Pública y de Bellas Artes se negaría finalmente a sufragar la partida correspondiente a su organización y realización por no celebrarse aquél en Madrid.

Este hecho explica que ya desde su inicio, y a diferencia de lo que ocurriría con el Festival, el protagonismo de la Delegación catalana y, en concreto, de Higini Anglès en los preparativos del Congreso fuera absoluto y a la vez la misma escasez de recursos públicos con los que se contó también fue motivo de la inmediata respuesta participativa de la sociedad civil barcelonesa en lo que respecta especialmente a la organización de los conciertos de "música antiga" que debían complementar las sesiones congresuales, y que según el testimonio de la crítica gozaron incluso de un mayor éxito de público que los conciertos programados en el Festival ${ }^{4}$.

3 [páginas autógrafas sueltas], Documentació Congrés, Fons Higini Anglès Biblioteca de Catalunya $(\boldsymbol{E}-B b c)$.

4 LLIURAT, (Barcelona, 1936). SAMPER, (Barcelona, 1936). La prensa generalista catalana siguió con gran interés tanto los conciertos de música contemporánea como los de música histórica, pero fueron los diarios La Veu de Catalunya y La Publicitat los que dedica-
Ya en la Acta del Consell de Cultura señalada del 02.03.1935 se confiaba a la misma Subponencia de Música la creación urgente de un Comité en su doble vertiente ejecutiva y de honor que debían sustentar el proyecto y es aquí donde pronto habían de incorporarse como miembros de honor la mayor parte de las entidades más destacadas en el panorama cultural y musical de la ciudad ${ }^{5}$, prácticamente las mismas que después iban a figurar como auspiciadoras de la Sección catalana del XIV Festival de la Sociedad Internacional para la Música Contemporánea. Por otra parte, se instituía una Comisión Organizadora ${ }^{6}$, así como un Comité Ejecutivo presidido por Pau Casals, y compuesto por dos vocales: Manuel Clausells y Francesc Pujol, y un secretario: Higini Anglès. Si tenemos en cuenta, además, que Robert Gerhard -personaje clave en la organización del Festivalfiguraba igualmente como miembro de la Comisión Organizadora del Congreso en calidad de responsable de la Subponencia de Música del Consell de Cultura, y que Pau Casals, el eminente artista que avalaba con su prestigio el proyecto musicológico de Anglès, iba a su vez a desempeñar junto con la Orquesta que él lideraba-La O.P.C- un papel fundamental

ron información más completa acerca de las sesiones del Congreso en sendas crónicas.

5 El Comité de Honor del Congreso, encabezado por Lluís Companys (President de la Generalitat de de Catalunya), Ventura Gassol (Conseller de Cultura) y Carles Pi i Sunyer (Alcalde de Barcelona) estuvo formado por las siguientes entidades: Consell de Cultura, Comissió de Cultura de l'Ajuntament de Barcelona, Institut d'Estudis Catalans, Universitat de Barcelona, Biblioteca de Catalunya, Conservatori del Liceu, Orfeó Català, Orfeó Gracienc, Patronat de l'Orquestra Pau Casals, Escola Municipal de Música, Associació de Música “da Camera", Associació Obrera de Concerts, Associació de Cultura musical, (Frank Marshall), Associació de Música Antiga, Germanor d'Orfeons de Catalunya, Acadèmia de Belles Arts de Sant Jordi, Academia de Bones Lletres, Ateneu Polytechnicum, Ateneu Enciclopèdic Popular, Obra del Cançoner Popular de Catalunya, Junta del Teatre del Liceu, Sindicat Musical de Catalunya, Associació de Mestres de Capella, Fundació Rafael Patxot.

6 La Comisión Organizadora del Congreso incorporaba los nombres de algunos de los representantes de las entidades que formaban parte del Comité de Honor así como los de las Delegaciones regionales españolas de la Sociedad Internacional de Musicología, elegidos directamente por Anglès. Composición de esta Comisión: Joaquim Folch i Torres (Presidente); Pau Casals (Vicepresidente); Alexandre Galí (Secretario); Higini Anglès (Vicesecretario); vocales: Jordi Rubió (Biblioteca de Catalunya), Lluís Millet (Orfeó Català), Josep Barberà (Conservatori del Liceu), Francesc Pujol (L'Obra del Cançoner), Robert Gerhard (Consell de Cultura de la Generalitat), Manuel Clausells (Associació de Música "da Camera"), Conrado del Campo, Josep Subirà, y Eduardo Martínez Torner (Delegación de Castilla), Baltasar Samper (Delegación de las Islas Baleares), Eduard López-Chávarri y Òscar Esplà (Delegación de Valencia), el Padre José Antonio de Donostia (Delegación del País Vasco), Manuel de Falla y Joaquín Turina (Delegación de Andalucía); Jesús Bal (Delegación de Galicia), Bonifacio Gil (Delegación de Extremadura). 
en la realización del Festival, será fácil entender la profunda simbiosis existente desde su misma génesis entre Congreso y Festival, dos acontecimientos que por si ello fuera poco compartían además un mismo centro logístico operativo: las dependencias de la Biblioteca de Catalunya a la que tanto mosén Anglès, en calidad de director de la Sección de Música desde 1917, como Robert Gerhard, nombrado en 1934 conservador adjunto del mismo departamento, estuvieron vinculados, y que se convirtió en sede y secretaría únicas del Congreso así como en el centro coordinador de la Sección catalana del Festival.

No obstante, conviene aclarar que si bien la convocatoria del XIV Festival Internacional para la Música Contemporánea fue dada a conocer en los medios de comunicación catalanes antes que la del III Congreso Internacional de Musicología y si la publicidad reservada al segundo pudo aprovecharse del hecho de presentarse de la mano del primero, como era lógico que sucediera dado el alcance siempre mucho más restringido de una reunión de sabios aunque la misma se ilustrase públicamente con conciertos, lo cierto es que no sólo en el orden cronológico sino también en el de las causalidades formales el Congreso ocupó el lugar prioritario. En efecto, fue en el último de los encuentros de la SIM en Cambridge en 1933 que quedó acordado que el próximo al cabo de tres años se celebrara en Barcelona pero en el caso de los festivales de la SIMC cuya periodicidad era anual los estatutos de la asociación prescribían expresamente que las candidaturas de nuevas ciudades debían presentarse sin otra antelación posible que la de un año, es decir que era en la propia asamblea ordinaria de socios convocada durante los días del Festival que se decidía por votación, a partir de las propuestas presentadas por las secciones nacionales, cuál sería la ciudad destinada a acoger el nuevo Festival del año siguiente, si bien es cierto que en Festival de la SIMC de Ámsterdam (1933) los catalanes ya habían propuesto informalmente su candidatura para $1936^{7}$. Consiguientemente, fue la elección previa y en firme de Barcelona por la SIM la que motivó y comprometió a los compositores españoles -y especialmente a los catalanes, que disponían de su propia Sección nacional en el seno de la Asociación- a presentar

7 SALAZAR, (Madrid, 1936). En la segunda de las quince entregas que el crítico y secretario del Comité de Madrid de la SIMC, Adolfo Salazar dedicó a los conciertos del Festival desde las páginas del diario El Sol de Madrid aclara este punto: la oferta hecha en Ámsterdam por la Sección catalana hubiera sido inviable económicamente sin la ayuda del gobierno central y la implicación consiguiente de la Sección española que firmó su compromiso de colaboración -con sus representantes en pleno: Enrique Fernández-Arbós, Òscar Esplà y el propio Adolfo Salazar- en la asamblea extraordinaria de la SIMC de 1935 en Praga. oficialmente la candidatura de Barcelona en la asamblea de la SIMC ${ }^{8}$ convocada urgentemente en Praga el mes de setiembre de 1935 poco antes de que se realizara excepcionalmente el Festival en la capital checa; y decimos que se trataba de una asamblea urgente porque en el último momento Karlovy-Vary (Carlsbad), había renunciado, sin previo aviso a los miembros de la Sección checa, a acoger el Festival de aquel año, lo que obligó a la SIMC a salir del paso como buenamente pudo trasladando improvisadamente aquella temporada el Festival a la capital checa a costa de reducir drásticamente el números de conciertos y por lo tanto el número de obras programadas.

En este ambiente un tanto enrarecido por los acontecimientos recientes Joan Lamote de Grignon, en su calidad de presidente de la Sección catalana de la SIMC, presentaba sucintamente la candidatura del XIV Festival Barcelona 1936 anunciando que en él iban a programarse tres sesiones de música orquestal, dos de música de cámara, además de una tercera dedicada a la interpretación de obras para orquesta de viento, y establecía una fecha provisional de celebración entre el 16 y el 23 de abril. En su alocución ante la Asamblea, Joan Lamote no se refirió en ningún momento -como tampoco lo hizo Robert Gerhard en la sesión del día siguiente- al Congreso de la SIM ni a los conciertos de música antigua que pensaban programarse juntamente con los de música contemporánea, pero en cambio sí sabemos que lo hizo en reunión privada mantenida con el Presidente Edward J. Dent poco después de su llegada a Praga, ya que así se lo comunica Lamote por carta ${ }^{9}$ a su amigo Anglès. En aquella entrevista Lamote y Dent convenían en el interés de hacer coincidir Festival y Congreso, y el músico catalán comunicaba a su colega británico la noticia reciente de la aceptación por parte de Lluís Millet y del Orfeó Català de participar con un solemne concierto de música antigua en los festejos del Congreso.

Pero el interés en Praga por salvar aquella temporada era más acuciante que las peticiones de aclaración pormenorizada de la candidatura barcelonesa, la cual quedó aprobada por mayoría con el compromiso expresado por Gerhard -en nombre de las Secciones española y catalana- de presentar en Barcelona las obras de los compositores que habían sido elegidas para ser interpretadas en Karlovy-Vary pero que

8 Correspondència del XIV Festival de Música Contemporània, Fons Higini Anglès Biblioteca de Catalunya $(\boldsymbol{E}-B b c)$.La Asamblea tuvo lugar en Praga, el jueves y viernes, días 5 y 6 de setiembre de 1935. Se guarda copia de la misma, transcrita en inglés.

9 LAMOTE, (Praga, 1935), Correspondència del III Congrés de la Societat Internacional de Musicologia, Fons Higini Anglès Biblioteca de Catalunya $(\boldsymbol{E}-B b c)$. 
por motivo del apresurado cambio de planes no pudieron finalmente escucharse en la capital checa ${ }^{10}$. Además, se admitía, tras votación, la lista elaborada por los españoles con los nombres de los miembros que debían constituir el tribunal ${ }^{11}$ para la selección de las obras que iban a programarse en la Ciudad Condal. Se establecía asimismo un plazo máximo: el 15 de diciembre de aquel mismo año, para la admisión de las composiciones concursantes que habían de ser enviadas indistintamente a las sedes de la SIMC en Madrid o en Barcelona, y se fijaba para las dos últimas semanas de diciembre en Barcelona la constitución del tribunal encargado de elegir un máximo de ocho composiciones en cada una de las dos secciones del Festival: la de música orquestal y las de música de cámara.

A partir de la resolución tomada en la Asamblea de la SIMC en Praga a principios de setiembre pudo hacerse pública la nominación barcelonesa como ciudad anfitriona a la vez del XIV Festival para la Música Contemporánea y del III Congreso Internacional de Musicología pero así como los preparativos del Festival siguieron desde este momento su marcha con relativa normalidad, la situación -como veremos- fue bien distinta en lo que se refiere al Congreso.

El Comité de Madrid de la organización del Festival pudo contar siempre con el soporte del Gobierno central gracias tanto a la influencia inmediata de personas directamente vinculadas a la administración -como Adolfo Salazar que además de ser el secretario del Comité de Madrid de la SIMC, lo era también de la Junta Nacional de Teatros y Museos- como al peso de figuras prominentes en la vida musical madrileña -como Enrique Fernández-Arbós, el director titular al frente de la Orquesta Sinfónica de Madrid que además era el presidente del Comité de Madrid de la SIMC-, aunque también es verdad que finalmente aquellas

10 Estas obras que se incorporaron automáticamente en la programación del XIV Festival, y por lo tanto no fueron revisadas por el tribunal reunido en Barcelona, fueron: Praeludium und Fuga, Op.10 del alemán Edmund Borck (interpretada en el Primer Concierto de Orquesta, en el Palau de la Música -en la misma sesión en la que hubo el estreno mundial del Concierto para violín y orquesta de Alban Berg; Overture de británico Lennox Berkeley (interpretada en el Tercer Concierto de Orquesta, en el Palau de la Música); Danza polonesa del polaco Roman Palester (interpretada en el Segundo Concierto de Orquesta, en el Palau de la Música); Overture del sueco Lars-Erik Larsson (interpretada en el Segundo Concierto de Orquesta, en el Palau de la Música); Sun-Treader del norteamericano Carl Ruggles (interpretada en el Segundo Concierto de Orquesta, en el Palau de la Música); la interpretación de la Cantata del checo Hans Feiertag, programada en Karlovy-Vary fue rechazada en Barcelona por el hecho de incluir coro y voces solistas, contingente con el que no se contaba en ninguno de los tres conciertos orquestales.

11 Este Tribunal lo formaron: Ernest Ansermet (Suiza), Joan Lamote de Grignon (Catalunya-España), Knudage Riisager (Dinamarca); Anton Webern (Austria); Boleslaw Woytowicz (Polonia). ayudas económicas fueran muy inferiores a lo solicitado y llegaran en vísperas mismo de la celebración del Festival ${ }^{12}$. Contrariamente, las cosas de presentaron desde el primer momento muy complicadas a la SIM para la realización de su proyectado Congreso por dos principales motivos: en primer lugar, por la naturaleza misma de un evento de carácter minoritario que como antes señalábamos, no tenía detrás la infraestructura administrativa y organizativa estables de una asociación como la SIMC con muchos afiliados en los distintos países y acostumbrada a convocar año tras año su festival internacional de música. Ésta no era indudablemente la situación mucho más precaria de la SIM que confiaba la organización trianual de su congreso internacional a la sola iniciativa personal y única responsabilidad de su comisario de turno, como ocurrió aquí en Barcelona. El Festival pudo ser fruto de muchos mientras que el Congreso tuvo desde el comienzo a mosén Higini Anglès como protagonista casi exclusivo: no solamente fue este musicólogo el autor del proyecto sino que también fue él el encargado de gestionarlo y de implementarlo hasta en sus más mínimos detalles; precisamente el carisma y el prestigio de que gozaba Anglès en el seno de la SIM contará como una de las razones esgrimidas por el presidente Edward J. Dent para defender, ante la presión de la Sección española de la SIMC para que el Congreso se hiciera en Madrid, la celebración del Congreso en Barcelona ${ }^{13}$. Y, en segundo lugar, tal como se desprende de la referida carta de Dent a Joan Llongueras, existió no solamente la negativa del Gobierno central a prestar ninguna ayuda para la realización del Congreso, sino -y esto es lo más grave- desde la misma Sección española de la SIMC se llevaron a cabo gestiones con el presidente de las dos asociaciones internacionales a fin de conseguir el traslado del

12 SALAZAR, (Madrid, 1935), Correspondència del III Congrés de la Societat Internacional de Musicologia, Fons Higini Anglès Biblioteca de Catalunya $(\boldsymbol{E}-B b c)$. Por esta carta sabemos que Enrique F. Arbós, a mediados de diciembre, todavía estaba haciendo gestiones para la obtención de la subvención para el Festival ante el nuevo ministro de Instrucción José Ballester, quien por su recién nombramiento poco debía saber acerca del tema. En carta escrita inmediatamente después por Salazar dirigida Anglès (datada en Madrid el 22.01.1936) aquél confirma a éste la concesión por parte del Ministerio de Instrucción de un crédito de 77.000 pts destinado al Festival. Pero deberemos esperar al nombramiento del nuevo ministro del ramo, Marcelino Domingo, tras el cambio de gobierno producido como consecuencia de las elecciones de febrero de 1936, para que finalmente Salazar vea -y se lo comunique a Anglès en carta del 20 de febrero- publicada en la Gaceta del 1 de febrero el Decreto del Ministerio de instrucción declarando oficial el XIV Festival del SIMC y autorizando al Ministro a arbitrar los créditos correspondientes.

13 DENT, (Cambridge, 1935), Correspondència del Congrés, Correspondència entre tercers, Fons Higini Anglès Biblioteca de Catalunya $(\boldsymbol{E}-B b c)$. 
encuentro internacional de musicólogos a la capital de España: ya que el Festival se hacía en Barcelona, lo lógico -se argumentaba- es que el otro evento tuviera sede en Madrid.

Con los dos grandes inconvenientes antes citados, a los que venía a sumarse la inseguridad social y política así como el marasmo administrativo que se vivían en Barcelona tras la suspensión de los órganos de gobierno autonómico derivados de los hechos de octubre del año anterior, no es de extrañar la incertidumbre de Higini Anglès y las dudas que le asaltaron desde el instante mismo en que se puso a trabajar en el proyecto del Congreso aproximadamente un año antes de su celebración. Las primeras labores debían ser las de la constitución de los Comités del encuentro, el establecimiento de un cuerpo mínimo de secretariado, así como la organización de las sesiones de música antigua; y nos atrevemos a establecer este orden de prioridades porque la gestión propiamente específica de contacto con los ponentes invitados, y de encargo y seguimiento de sus comunicaciones, no aparecen hasta muy tarde en la correspondencia de Higini Anglès, hasta finales de 1935. No obstante, el estado embrionario en que se hallaba todo todavía, y el giro tomado por los últimos acontecimientos políticos que podían dejar fácilmente en papel mojado los acuerdos de gobierno de la Generalitat y del Ayuntamiento relativos a la ayuda y financiación del Congreso, suponemos que fueron circunstancias que impelieron a Anglès a escribir al secretario de la SIM en Basilea, Wilhelm Merian, exponiéndole francamente sus temores. En su respuesta, que debió producirse el mismo mes de abril, Merian sugería que ante esta difícil situación lo más sensato era interrumpir los trabajos del Congreso y posponer este encuentro hasta 1939 en la misma capital catalana; mientras tanto y con objeto de salvar la convocatoria de 1936, el secretario de la SIM proponía organizar una pequeña reunión de musicólogos en la misma Basilea, sede de la SIM.

Esta carta, que no hemos encontrado en el Fondo Anglès, debió recibirla su destinatario por los mismos días -a mediados de abril- en que Higini Anglès se disponía a comenzar a trabajar a fondo en la organización del encuentro. Y era lógico pues que una vez recibida, el musicólogo catalán se pusiera en contacto directamente con el presidente de la SIM para que éste le confirmara lo escrito por el secretario. Así, en carta a Dent pocos días después ${ }^{14}$, el musicólogo le escribe, en catalán, lo siguiente:

«la nova situació política ha imposat, d'entrada, un període d'interinitat, durant el qual el govern de la Generalitat no ha fet més que anar canviant constantment

14 ANGLÈS, (Barcelona, 1935), Correspondència del Congrés, Fons Higini Anglès Biblioteca de Catalunya $(\boldsymbol{E}-B b c)$. les persones responsables. Totes les nostres gestions esdevenen inútils en cada canvi. Malgrat tot, ja havíem obtingut el recolzament de la Generalitat i de l'Ajuntament i esperàvem obtenir el de Madrid. En aquesta situació vaig rebre una carta del professor Mérian de Bâle en la qual m'exposava que, vistes les dificultats que jo li havia prèviament comunicat, aconsellava que per a l'any 1936 fóra més eficaç de celebrar una petita reunió de savis a Bâle i posposar el congrés de Barcelona el 1939. En veure aquesta proposició, vam interrompre les gestions i és en aquest sentit que vaig escriure Mérian el mes de maig; suposo que ell us va informar però en veure que no m'ha tornat a escriure, volia exposar-vos personalment la situació».

La respuesta ${ }^{15}$ del presidente de la SIM no se hizo esperar. Dent desmentía en ella, como no oficial, la propuesta emitida por el secretario de su asociación a la vez que reiteraba su deseo de perseverar en la idea original del binomio Festival-Congreso para Barcelona 1936, sobre todo después del reconocimiento público obtenido: si la Generalitat y el Ayuntamiento habían apoyado la organización del Congreso, con mucha más motivo defenderían la idea de que ambos acontecimientos, Festival y Congreso, coincidieran en el tiempo en la misma ciudad:

«En ce cas, je m'imagine que les autorités comme la Generalidad et la Municipalité appuieraient beaucoup plus cordialement un Festival des deux Sociétés qu'un Festival seulement de la SIMC, et j'ai peur que si vous abandonnez l'idée du Congrès, cela rendrait plus difficile la situation pour la SIMC ».

Dent insistía además en la necesidad de compensar el excesivo predominio que el bloque centroeuropeo (Alemania y Austria) había estado ejerciendo en las dos asociaciones desde su misma fundación. Reforzar la colaboración de los países meridionales tanto en la SIM como en la SIMC era una forma de contrarrestar la voz dominante de los musicólogos y compositores de habla alemana, y ello era especialmente oportuno en un momento como el presente en que la política cultural alemana iba adquiriendo un tono nacionalista cada vez más agresivo y excluyente. Por esto era importante para Dent, en aquel contexto europeo de tensión política creciente, que se celebraran los encuentros y que una ciudad mediterránea como Barcelona, situada en la periferia del centro germánico los alojara durante la misma semana:

15 DENT, (Cambridge, 1935), Correspondència del Congrés, Fons Higini Anglès Biblioteca de Catalunya $(\boldsymbol{E}-B b c)$. 
«Le Festival de la SIMC est d'une grande importance,en vue des activités des Nazis et des musiciens réactionnaires en Allemagne, qui ont constitué une nouvelle Societé Internationale sous la présidence de Richard Strauss. On vient de donner un Festival à Hambourg; L'Angleterre y était représentée, mais seulement par des compositeurs morts !!! (...) Voici où entre l'Espagne. Pour toutes les deux sociétés la collaboration espagnole est devenue d'importance capitale »

Y una vez más el presidente de la SIM supo actuar diligentemente al decidir contactar directamente con Enrique F. Arbós y Joan Llongueras (respectivamente presidente y secretario de las dos secciones españolas de la SIMC) instándoles a que se hicieran cargo cuanto antes de un problema que no estaba en manos de mosén Anglès el poder resolver. $Y$ estas misivas debieron tener algún efecto ${ }^{16}$ porque a comienzos de agosto el musicólogo catalán escribe a Dent ${ }^{17}$ diciéndole que admitidos sus consejos está dispuesto a seguir trabajando en los preparativos del Congreso, aunque le advierte que salvado el escollo de la inestabilidad política en Catalunya sigue existiendo el no menos grave de la falta de recursos económicos:

«Je vous remercie de votre aimable lettre du 27 juin. Vous avez raison et je suis absolument d'accord avec vous au sujet de l'avantage de célébrer simultanément le Congres de Musicologie et le Festival de la SIMC à Barcelone en 1936. Mais comment pouvais-je continuer les démarches à cette fin, si en plein moment critique la lettre du Dr. Mérian m'invitait aimablement à ajourner nos desseins ? Je ne vous ai pas répondu plus tôt, parce que je ne me sentais pas décidé à renouer ces liens rompus. Toutefois, votre insistance auprès de Mrs. Llongueras et Arbós me stimule a changer d'avis, et je me décide à exprimer mon désir de reprendre nos efforts, et si vous acceptez pour le Congres les conditions et les plans que je me permets de vous soumettre à continuation. De toute façon, je ne ferai rien avant d'avoir reçu votre consentement.

16 ANGLÊS, (Barcelona, 1935), Correspondència enviada per Higini Anglès a destinataris no identificats, Fons Higini Anglès Biblioteca de Catalunya $(\boldsymbol{E}-B b c)$. Fruto, seguramente, de las gestiones efectuadas con rapidez por Dent desde Cambridge fue la reunión que debió mantenerse en la Biblioteca de Catalunya por los máximos responsables en Catalunya del Festival y Congreso: Pau Casals, Robert Gerhard, además de Jordi Rubió y otros, y de la cual Higini Anglès -allí también presente- informa en carta manuscrita al presidente del Consell de Cultura, Joaquim Folch i Torres.

17 ANGLÈS, (Barcelona, 1935), Correspondència del Congrés, Fons Higini Anglès Biblioteca de Catalunya $(\boldsymbol{E}-B b c)$.
Je dois bien vous dire que pour ce qui touche au budget, après le 6 d'octobre le Gouvernement de Madrid et à plus forte raison le Gouvernement de Catalogne, n'ont qu'une seule idée : réduire au minimum toutes les dépenses. En toute franchise j'ajoute que si j'acceptai si promptement la suggestion de Dr. Mérian -que d'autre part j'estimais officielle- ce fut surtout dans l'idée de favoriser la célébration du Festival de la SIMC, puisque l'appui promis par nos corporations se serait trouver assez maigre pour suffir à l'organisation du Congres et du Festival simultanées, par contre il aurait permis célébrer les concerts de musique moderne seuls en toute dignité ».

Reducir los gastos, continúa Anglès, significaba obligatoriamente aplicar recortes en la programación musical del Congreso y prescindir de la interpretación de dos obras ${ }^{18}$ que figuraban en el proyecto inicial: «Nous serons donc obligés de supprimer la représentation de l'opéra de Domenico Terradellas (le rival de Jommelli) ou de Martin et Soler, que nous avions prévue, de même que celle de Pedrell »; de todas maneras, seguía en firme la idea de celebrar un concierto en Montserrat con los monjes y la escolanía de aquel monasterio como protagonistas (con un programa de música hispana de los siglos XIII al XV), y se contaba además con una sesión a cargo del Orfeó Català (madrigales hispánicos). Anglès aún pensaba traer a Barcelona alguna coral bilbaína para que actuara en un tercer concierto con una programación dedicada a la polifonía religiosa española de los siglos XV-XVI; y también le avanzaba a Dent la idea de introducir una nueva sección en la programación de las sesiones académicas del Congreso: una sección que estuviera específicamente dedicada al folklore musical hispano, que debería tener su expresión en un concierto final de danzas típicas y de cantos regionales como colofón del encuentro.

Con un programa musical más o menos perfilado, sin embargo lo más perentorio -añadía Anglès en aquella misma carta del 2 de agosto- era hacer frente al tema económico y conseguir de Madrid el mínimo aproximado de 30.000 pts que se sumarían a las cantidades aportadas por el Gobierno catalán y que permitirían garantizar la viabilidad al proyecto:

«Malgré tout il nous faudra bien 30.000 pts pour les auditions restantes et autres dépenses du Congres. J'estime qui serait encore possible pour les auditions restantes et autres dépenses du Congres. J'estime qu'il serait encore possible d'obtenir cette somme du Gouvernement

18 Correspondència del Congrés, Fons Higini Anglès Biblioteca de Catalunya $(\boldsymbol{E}-B b c)$. En un primer momento Anglès había comentado con Josep Subirà la posibilidad de montar la reposición de la ópera $A r$ temisia de Domenico Terradellas. 
de Madrid, si les maîtres Falla et Arbós voulaient bien faire valoir toute leur influence à cette fin. Dans ce cas, outre la bonne organisation des tâches du Congres, nous pourrions offrir hospitalité à Barcelona aux membres du Comité directif et du Secrétariat de la Société I. de Musicologie, et peut-être même subvenir à quelques frais de déplacement et voyages, selon vos indications ».

Higini Anglès no quería comenzar sus breves vacaciones estivales de aquel año sin dejar antes iniciadas las gestiones para la obtención de la ayuda ministerial y de acuerdo con lo anunciado a Dent en la carta citada, escribe inmediatamente dos misivas a Manuel de Falla en un intervalo de dos día para pedirle su intercesión en este tema ante el Gobierno español ${ }^{19}$.

«Tratándose del hecho que los temas del Congreso son todos sobre temas de música española, tratándose además de dar a conocer al mundo musical exclusivamente obras históricas del repertorio español no sería cosa extraordinaria el que el Gobierno de Madrid votara una consignación de esta índole -Anglès pide 30 o 35.000 pts- para sufragar los gastos del Congreso. Tal como están las cosas, la subvención sería para nosotros segura si Ud., con toda su personalidad, solicitara del Ministro de Instrucción Pública esta cantidad. -La petición de Ud., ayudada con la otra del Maestro Arbós, será decisiva. Sin esta ayuda del Gobierno no sería posible ni siquiera hablar del Congreso; ello sería muy de lamentar dejarnos pasar una ocasión tan propicia».

No sabemos si Manuel de Falla, como Anglès le solicitaba, hizo algo al respecto -como en cambio sí conocemos la respuesta pesimista recibida de Enrique F. Arbós ${ }^{20}$ a quien Anglès debía haberse dirigido por las mismas fechas y con igual propósito- porque aquel tema es eludido por el maestro granadino en su contestación de comienzos de setiembre en la que Falla declina la otra petición que Arbós le hacía en su carta: la de interceder ante el Ministro a fin de obtener una subvención que permitiera el desplazamiento de la Coral Vasca a Barcelona para que actuara en uno de los conciertos del Congreso, cosa a la que Falla no se avino debido a su vin-

19 ANGLÊS, (1935), Correspondència del Congrés, Fons Higini Anglès Biblioteca de Catalunya $(\boldsymbol{E}-B b c)$. Las cartas mecanografiadas enviadas por Higini Anglès a Manuel de Falla están datadas los días 4 y 6 del mes de agosto.

20 FERNÁNDEZ-ARBÓS, (Madrid, 1935), Correspondència del Congrés, Fons Higini Anglès Biblioteca de Catalunya $(\boldsymbol{E}-B b c)$. En esta carta Arbós dejaba muy claro que el Ministerio sólo aportaría fondos para el Congreso en el caso de que éste se hiciera en Madrid, cosa a la cual se oponía decididamente el presidente Edward J. Dent. culación personal y profesional con la otra gran formación coral de Euskadi: el Orfeón Donostiarra. Lo que sí es seguro es que si la carta de Anglès la hubiera recibido Falla después de que a éste le llegara la programación impresa y definitiva de Festival y Congreso, Anglès nunca habría tenido en el compositor El sombrero de tres picos al aliado deseado. Y es que Falla se disgustó profundamente al saber, ya en plenas vísperas de la celebración, que detrás de la organización de ambos eventos no estaban solamente las respectivas secciones o delegaciones españolas de la SIMC y de la SIM, como únicas representativas del Estado y por lo tanto únicas interlocutoras en su relación con las asociaciones internacionales; además de las españolas existían una Sección y una Delegación catalanas, en perfecta paridad organizativa con las primeras. Es esto precisamente lo que molesta a Falla y lo que expresa en su posterior carta ${ }^{21}$ a Anglès:

«En ello -Falla se está refiriendo a las programaciones de Festival y Congreso- hay cosas que me producen gran satisfacción pero otras me causan amargura: $1^{\circ}$ a la denominación de "Secció catalana" que se da al Comité de Barcelona, y $2^{\circ}$, a la designación nacional de los compositores catalanes separándolos de los de España. (...) Soy el primero de hacerme cargo del noble y legítimo orgullo de ustedes por la organización -y realización de dichos actos, como también de sus deseos que así se manifieste, y pienso que ello puede perfectamente destacarse con la denominación de GRUPO, SECTOR u otra análoga que no rompa (como la de "Secció") la unidad de la Sección general de España. Y en cuanto a la segunda cuestión, igualmente delicada, creo sin duda que no han considerado ustedes exactamente la grave trascendencia que, por tratarse de un congreso INTERNACIONAL, tiene la separación de nacionalidad que figura en el programa que figura en el programa del Festival entre catalanes y españoles no catalanes. Esto me parece tan claro que estoy seguro de que ustedes verán la imprescindible necesidad de añadir el nombre de España al de Cataluña. Así, por ejemplo: (España: Cataluña)».

Lo que Manuel de Falla manifestaba en su carta, se hacía eco del sentir general al menos dentro de las instancias administrativas gubernamentales que era las que decidían en materia de concesión pública de recursos para proyectos culturales españoles. Y este fue el muro que encontró Higini Anglès y que intentó insistentemente sortear sin éxito, ya que finalmente nunca llegaron del Ministerio de Instrucción aquellas 30.000 pesetas solicitadas.

21 FALLA, (Granada, 1936), Correspondència del Congrés, Fons Higini Anglès Biblioteca de Catalunya $(\boldsymbol{E}-B b c)$. 
Así las cosas, Higini Anglès disponía a finales de 1935 -y no sabemos si llegó nunca a percibir el resto de lo solicitado de las administraciones catalanas para el año $1936^{22}$ - y, según lo que indicábamos más arriba, de las 20.000 pts aportadas a partes iguales (10.000 cada una) por la Generalitat y el Ayuntamiento de Barcelona.

Existía a favor del organizador el bajo coste económico de la parte estrictamente académica del Congreso ya que -como ocurre en la mayor parte de los congresos internacionales de tipo humanísticos- los comunicantes participantes debían pagarse ellos mismos -o sus respectivas secciones nacionales de la SIM- no sólo los desplazamientos y estancia en Barcelona sino también su matrícula de inscripción; las invitaciones, en cualquier caso, fueron excepcionales: como la del gregorianista Dom Joseph Gajard de Solesmes, o la de Johannes Wolff ${ }^{23}$ que junto a otros musicólogos judíos alemanes -entre ellos, Alfred Einstein y Curt Sachs - y habiendo caído en desgracia desde hacía muy poco ante las autoridades nazis atravesaban una situación laboral y económica muy precarias; a la postre, ni Johannes Wolf ni Alfred Einstein -sí lo hizo Curt Sachs- vinieron a Barcelona aunque Einstein sí envió una comunicación que pudo ser leída en el Congreso.

Tampoco constituía ningún problema el lugar para la celebración de las sesiones académicas: las dependencias de la nueva sede del Institut d'Estudis Catalans en la Casa de

22 Correspondència del Congrés, Fons Higini Anglès Biblioteca de Catalunya $(\boldsymbol{E}-B b c)$. Sí conocemos que, en referencia al Congreso, el Ayuntamiento de Barcelona, aportó 6000 pts de las 10.000 concedidas para 1936; y ello lo sabemos por la carta que Anglès envía a Rafael Patxot, el 10.07.1936, en la que el musicólogo catalán solicita al mecenas ayuda para la publicación de las Actas del Congreso.

23 En relación a Johannes Wolff, entre los documentos autógrafos de Higini Anglès contenidos en el Fons Personal Higini Anglès existen muchas referencias a la que se da por segura presencia del musicólogo en el Congreso, de la que sabemos incluso que tenía pensado presentar una comunicación sobre "el tratado atribuido a Ramos de Pareja". En una carta que Anglès (ANGLÈS, 1935) envía al hispanista John Brande Trend, amigo y colaborador de Dent en Cambridge, el secretario del Congreso incluso llega a temer por la muerte de Wolff dado que no contestaba desde hace tiempo a ninguna de sus cartas. Sin embargo en posterior misiva de Anglès a Dent (ANGLÈS, 1936).En esta carta -que está inventariada entre las que no consta el nombre del destinatario, aunque por el contendido se desprende que se trataba sin duda alguna de Edward J. Dent-, Anglès comunica al presidente de la SIM que una vez puesto en contacto con Wolff, se le enviaría el dinero desde Barcelona vía postal, para el viaje en tren: Berlín-Barcelona/ Barcelona-Berlín. El caso de la situación de los musicólogos judíos alemanes cada vez más amenazados en su país, preocupó especialmente a Dent, y a través de su correspondencia con Anglès en referencia al Congreso, sabemos que desde la sede central de la SIMC de pudo influir directamente en la Embajada del Reino Unido en Berlín para que la presencia de los compositores y musicólogos alemanes en el Festival y el Congreso de Barcelona se convirtiera en asunto de alto interés diplomático. la Convalecencia situada dentro del histórico complejo del Hospital de la Santa Creu, del que también formaba parte la que es hoy Biblioteca Nacional de Catalunya trasladada allí igualmente desde hacía tres años. Tanto el Institut d'Estudis Catalans como la Biblioteca de Catalunya, representados ambos por Jordi Rubió, eran miembros de honor del Congreso y Jordi Rubió formaba parte de su Comisión organizadora, por lo que Higini Anglès pudo disponer gratuitamente de aquel recinto. Así pues, y dejando a un lado la imprescindible inversión en publicidad y en la publicación del programa general del Congreso, la parte del mismo que podía quedar más seriamente perjudicada por la escasez de recursos económicos era la relativa a los conciertos de música antigua proyectados como complementación de las sesiones académicas dos de los cuales, como ya hemos comentado, Anglès -a finales de agosto de 1935- los daba por seguros: el de l'Orfeó Català en el Palau de la Música y el de la escolanía y los monjes de Montserrat en su Monasterio. El resto, en estos momentos, quedaba todavía por determinar aunque se pensaba incluir una ópera (al principio Anglès y su amigo Josep Subirà estuvieron barajando la posibilidad de llevar al escenario Artemisia de Domènec Terradellas, si bien las dificultades en la obtención y transcripción de los materiales correspondientes a aquella partitura los inclinaran a elegir finalmente una obra mucho más factible de reponer: Una cosa rara, ossia Bellezza ed onestà del compositor valenciano, coetáneo de Mozart, Vicent Martí i Soler, ópera de la que se conmemoraba precisamente el 150 aniversario de su estreno en Viena), y un festival de danzas populares españolas que serviría de colofón a los actos del Congreso.

\section{Estructura del Congreso}

Tras el reposo estival es cuando Higini Anglès emprende de verdad las labores de preparación del Congreso con acciones muy concretas: primero, asegurar la participación de la musicología española en la que estuvieran representadas sus principales demarcaciones históricas y geográficas lo que implicaba el urgente nombramiento coordinadores regionales que, por derecho propio, pasasen a integrarse en la Comisión organizadora del Congreso; en segundo lugar, Anglès debía concentrase en lo que constituye el aspecto medular de todo congreso: la propuesta y encargo de comunicaciones científicas a algunas de las personalidades más eminentes en aquel momento en el ámbito internacional de la musicología; y, finalmente era necesario concretar las sesiones de música histórica así como los detalles de la fiesta de danzas populares españolas que pensaba convocarse como clausura popular del Congreso en el Poble Espanyol dentro del recinto ferial de la Montaña de Montjuïc. 


\section{A/ Coordinación con el resto de comunidades}

En la elección de coordinadores regionales Anglès pensó que la mejor manera de comprometerlos era encargándoles directamente una comunicación científica. Esto es lo que comprobamos en las respuestas de aceptación de algunos de los nuevos coordinadores y que se conservan en el Fondo Anglès. Todos ellos eran conocidos, si no directamente amigos, de Anglès, y en sus cartas dan al musicólogo catalán el título de la comunicación que piensan exponer en el Congreso. Conrado del Campo ${ }^{24}$, Josep Subirà25 y Eduardo Martínez Torner ${ }^{26}$ eran los encargados de representar a Castilla; Baltasar Samper $^{27}$, a las Islas Baleares; Eduardo López-Chávarri ${ }^{28}$ y Òscar

24 DEL CAMPO, 1936, Correspondència del Congrés, Fons Higini Anglès Biblioteca de Catalunya $(\boldsymbol{E}-B b c)$. En esta carta, además de aceptar las propuestas, comunica a Anglès el título de su ponencia: Algunas ideas en torno de la armonización (sentido estético de la armonización del canto popular (comunicación guardada en el Archivo Anglès).

25 SUBIRÀ, 1936, Correspondència del Congrés, Fons Higini Anglès Biblioteca de Catalunya $(\boldsymbol{E}-B b c)$. Josep Subirà fue el hombre de Anglès en Madrid para los temas del Congreso. Él fue su asesor en el tema de la programación de las sesiones musicales; fue su valedor en las gestiones con la Administración, y fue también después su defensor ante algún que otro repunte airado surgido en la prensa de la capital española ante lo que algunos consideraron excesivo protagonismo de los catalanes en un congreso que puesto que organizado por una asociación internacional hubiera debido estar mucho más vehiculado desde su Sección española. Josep Subirà presentó dos comunicaciones en el Congreso: Un fondo desconocido de música para guitarra y La música instrumental al servicio de las obras dramáticas declamadas, aunque ninguna de ellas aparece guardada en el Archivo Anglès. Concretamente, en la carta mecanografiada de Josep Subirà y dirigida a Pau Casals de 16.02.1936, Josep Subirà acepta y agradece su elección al presidente del Comité ejecutivo del Congreso. Además, Josep Subirà contratacó el juicio reticente respecto al Congreso emitido por Adolfo Salazar desde las páginas de El Sol con otro largo artículo donde se hacía una encarecida defensa de la labor llevada a cabo por Higini Anglès en el diario El Socialista de la capital española.

26 Correspondència del Congrés, Fons Higini Anglès Biblioteca de Catalunya $(\boldsymbol{E}-B b c)$. Eduardo Martínez Torner es citado en la correspondencia entre Josep Subirà y Higini Anglès. Al final aunque aceptó el nombramiento no pudo asistir al Congreso. De todas formas envió al mismo una comunicación: Los ritmos en la música popular castellana (comunicación no guardada en el Archivo Anglès).

27 Correspondència del Congrés Fons Higini Anglès Biblioteca de Catalunya $(\boldsymbol{E}-B b c)$. Baltasar Samper participó activamente en el Congreso; presentó una comunicación $E l$ cant de les cançons de treballada a Mallorca, ilustrada durante su lectura con el canto de dos campesinos mallorquines (comunicación guardada en el Archivo Anglès) ; y fue también Samper quien desde las páginas del diario La Publicitat supo hacer una mayor difusión del evento en la prensa catalana.

28 LÓPEZ-CHÁVARRI, 1936. Correspondència del Congrés, Fons Higini Anglès Biblioteca de Catalunya $(\boldsymbol{E}-B b c)$. Eduardo LópezChávarri contestó a Anglès comunicándole al secretario del Congreso que, a causa de una enfermedad, no podría acudir a Barcelona. Tampoco envió ninguna comunicación al Congreso.
Esplà $^{29}$, coordinaban la comunidad valenciana; el Padre Do$\operatorname{nostia}^{30}$ al País Vasco; Manuel de Falla ${ }^{31}$ y Joaquín Turina ${ }^{32}$ representaban a Andalucía; Jesús Bal y Gay ${ }^{33}$ a Galicia; y Bonifacio Gil García ${ }^{34}$ a Extremadura. La metodología de tra-

29 Òscar Esplà era a la vez vicepresidente del Comité de Madrid del XIV Festival de la SIMC, aunque no presentó ninguna comunicación en el Congreso. De este compositor se interpretó su cantata $\mathrm{La}$ nochebuena del diablo en el último de los conciertos del Festival de la SIMC dedicado a música española contemporánea.

30 ANGLÈS, Correspondència del Congrés, Fons Higini Anglès Biblioteca de Catalunya $(\boldsymbol{E}-B b c)$. En carta autógrafa no datada, Higini Anglès pide al Padre José Antonio Donostia que éste haga las oportunas gestiones ante la Diputación guipuzcoana y el Ayuntamiento de San Sebastian para que obtuviera de ambas administraciones el compromiso de hacerse cargo de los gastos de desplazar hasta Barcelona a un grupo de bailarines y chistularis vascos para actuar en el festival de danzas populares del Poble Espanyo. El Padre Donostia presentó una comunicación en el Congreso: La música de Juan Anchieta, siglos XV-XVI.

31 ANGLÈS, 1935 /1936. Correspondència del Congrés, Fons Higini Anglès Biblioteca de Catalunya $(\boldsymbol{E}-B b c)$.En el epistolario del Archivo Anglès se conservan cuatro cartas intercambiadas entre Higini Anglès y Manuel de Falla a propósito del Congreso, dos emitidas por Anglès (datadas el 04-08-1935, y el 06-08-1935) y dos por Falla (datadas el 02-09-1935 y el 07-02-1936), de las cuales ya hemos hecho mención. Falla debió aceptar su nombramiento de coordinador regional, junto con Joaquín Turina, por Andalucía, a pesar del incomodo manifestado. El aval que podía aportar el maestro granadino era fundamental para Anglès de cara a garantizar el éxito de todo el proyecto. A Falla se le pide que interceda ante el Ministerio de Instrucción en el tema de la solicitud de subvención así como en de la asunción de los costes del desplazamiento a Barcelona de la Coral Vasca para uno de los conciertos programados, gestiones ambas que resultaron infructuosas.

32 TURINA, Correspondència del Congrés, Fons Higini Anglès Biblioteca de Catalunya $(\boldsymbol{E}-B b c)$. Joaquín Turina aceptó ambos nombramientos: el de coordinador del Área andaluza y el de figurar como miembro del Comité organizador del Congreso en carta remitida a Anglès desde Madrid, y no datada, donde le comunicaba la recepción del oficio por parte del Gobierno de la Generalitat en el que figuraba su nombramiento. En él Turina proporcionaba además al secretario del Congreso el título de la comunicación que pensaba presentar: $E l$ canto popular andaluz (comunicación guardada en el Archivo Anglès). Joaquín Turina tuvo un importante papel en las jornadas -recordemos que en el concierto orquestal final de Festival de la SIMC dedicado a música contemporánea española se interpretó el fragmento A orillas del Guadalquivir perteneciente a su Sinfonía sevillana- ya que no sólo expuso personalmente su comunicación sino que asistió a los conciertos y sesiones del Festival y Congreso en su condición de corresponsal y comentarista del diario El Debate de Madrid.

33 BAL Y GAY, (Madrid, 1935), Correspondència del Congrés, Fons Higini Anglès Biblioteca de Catalunya $(\boldsymbol{E}-B b c)$. Jesús Bal y Gay aceptó su nombramiento de representante de Galicia en carta escrita desde Madrid dirigida a Anglès del 2 de setiembre de 1935. En ella comunica al secretario del Congreso el título de su comunicación: $L a$ canción amorosa de la Corte de Castilla de fines del siglo XVI y principios del siglo XVII. Jesús Bal asistió a las sesiones del Congreso y nos consta que leyó su comunicación aunque ésta no figure guardada en el Archivo Anglès.

34 GIL, Correspondència del Congrés, Fons Higini Anglès Biblioteca de Catalunya $(\boldsymbol{E}-B b c)$. Bonifacio Gil aceptó su nombramiento de representar Extremadura aunque en carta a Anglès escrita desde Ba- 
bajo seguida en la organización del Congreso poco tenía que ver pues con la observada en el Festival dónde, por tratarse de una competición, eran los propios compositores españoles los primeros interesados en presentar sus obras y exponerlas al fallo de un jurado internacional establecido de antemano por la SIMC; por el contrario, en el caso del Congreso, Anglès contaba con la realidad de un perfil escaso de motivación en los musicólogos españoles en absoluto acostumbrados a participar en encuentros de este tipo; de hecho, esta era la primera vez que se organizaba un congreso internacional de musicología en España por lo que en la elección de los representantes regionales Higini Anglès no estaba únicamente decidiendo circunstancialmente las personas y los contenidos que cada una de ellas pudiera tratar en una reunión de científicos sino algo mucho más trascendente, y era sentar las bases para una deseable y sólida coordinación entre las comunidades históricas hispanas en el estudio de sus músicas una vez que la musicología, en aquellos momentos una ciencia todavía en sus albores en nuestro país, se implantara firmemente de acuerdo con los paradigmas de los países más avanzados en aquella materia. El Congreso significaba para Anglès la oportunidad irrepetible de consolidar, al amparo de un organismo internacional, el desarrollo de la musicología en España y la conciencia de este hecho comportaba un grado de implicación en el proyecto que era ajeno en gran medida al ánimo de los organizadores del Festival.

\section{B/ Secciones o ámbitos del Congreso}

En lo referente a los aspectos estrictamente científicos del Congreso, es decir, su estructuración en ámbitos temáticos y su listado de comunicaciones, lo que significaba contactar con los ponentes y encargarles sus ponencias, no observamos signos de actividad en el epistolario de Higini Anglès hasta comienzos de otoño de 1935; entonces Anglès sí debió ponerse a gestionar con intensidad este tema si nos atenemos a la correspondencia consultada. En realidad, Anglès tenía ante sí situaciones bien contrastadas ya que si por un lado contaba con delegaciones nacionales de la SIM como las de Alemania o Austria lo suficientemente organizadas para que sus miembros se enteraran al punto de la convocatoria barcelonesa e hicieran conocer inmediatamente a Higini Anglès su interés en asistir al Congreso y presentar allí sus comunicaciones, en el caso de otros países que no

dajoz y no datada, comunica al secretario del Congreso su imposibilidad de asistir a los actos del mismo. Sin embargo, fueron leídas dos comunicaciones suyas en el Congreso: Extremadura y la posible regionalización de su música popular y La tradición en la canción extremeña (ambas guardadas en el Archivo Anglès). gozaban de aquella tradición musicológica y en que por lo tanto sus delegaciones en el seno de la SIM no funcionaban con la misma eficacia, tuvo que ser el mismo Higini Anglès quien fuera a la búsqueda de sus posibles comunicantes ${ }^{35}$.

En el caso de Alemania no obstante, se produjo otro tipo de dificultad derivada del creciente control cultural ejercido por las autoridades nazis. A la delegación alemana de la SIM, el nuevo gobierno nacionalsocialista le había retirado su soporte para dárselo en cambio a una antigua institución berlinesa: el Instituto Estatal para la Investigación Musical (Staatliches Institut für deutsche Musikforschung) que se convertía ahora, tras el cese fulminante de uno de sus máximos responsables, Curt Sachs y de otros investigadores de origen judío, en el organismo oficial representativo del sector. Lo mismo había ocurrido con la sección alemana de la SIMC -el núcleo desde el que se había gestado precisamente aquella organización internacional- caída igualmente en desgracia a favor de una nueva asociación de compositores, intérpretes y educadores, el Instituto de Música del Estado (Reichsmusikkamer) cuya presidencia -como comentaba Dent en su carta a Anglès- fue confiada al compositor Richard Strauss. En esta coyuntura política que empezaba a predecir el trágico sesgo que iban a tomar las cosas en Alemania y en todo el mundo tan sólo unos pocos años después del encuentro en Barcelona, es fácil entender la insistencia de Dent, presidente de las dos asociaciones internacionales excluidas por la exaltación del nacionalismo racista del gobierno alemán, para que Festival y Congreso concurrieran en la capital catalana según el calendario previsto, y para que ambos eventos se erigieran en una manifestación de defensa de los valores musicales democráticos en una Europa amenazada $^{36}$.

35 Existe en Archivo Anglès un abundante número de cartas enviadas por Anglès a distintos musicólogos de distintos países solicitando su participación en el Congreso que fueron contestadas siempre con agradecimiento pero excusando, por diferentes causas, la imposibilidad de acudir o de enviar comunicaciones a las jornadas. Es el caso, por ejemplo, de Jacques Chailley, quien comunica a Anglès su intención de verse ya que a pesar de no poder asistir, va a estar en Barcelona a principios del mes de abril con motivo de la representación en dicha ciudad de Le miracle de Théophile y de Le jeu de Marion a cargo del grupo teatral universitario Théophiliens que él preside.

36 En el prólogo que escribe Edward J. Dent para el extenso programa de mano del Festival, el presidente de la SIMC, desmentía con energía la imputación de que dicha asociación estaba promoviendo en sus festivales un estilo de música internacional desprovista de individualidad; precisamente la defensa de la expresión individual del compositor, sostenía Dent, era su mejor antídoto frente a la deshonestidad en que a menudo incurrían en aquel momento los estereotipos nacionalistas, y no sólo musicales sino también políticos: «el mundo entero adolece la enfermedad de un nacionalismo exagerado y la música, más que nunca, precisa un espíritu de cooperación internacional». 
De todas maneras, el antisemitismo recientemente adoptado en la política cultural alemana afectó en cierta manera el discurrir del Congreso mientras que sus proclamas nacionalistas y de repulsa al arte moderno "degenerado" no tuvieron, en cambio, ningún impacto en la programación musical de un Festival que, por el contrario, contó con abundante número de obras adscritas directa o indirectamente a la tradición del vanguardismo centroeuropeo. Y es que en definitiva los musicólogos dependían más directamente que los compositores de las instituciones públicas en las que trabajaban como investigadores o profesores por lo que la radicalización ideológica del partido en el poder comportó en muchos casos-primero por motivos raciales, y más adelante por discrepancias ideológicas- su despido y el inicio de una diáspora incierta que impidió, como apuntábamos, la presencia en Barcelona de Johannes Wolff o Alfred Einstein; pero al margen de estas dos deserciones, la musicología germánica (austríaco-alemana), a pesar de todos los inconvenientes, continuó siendo -por las razones más arriba señaladas a las que deberíamos inmediatamente añadir la natural querencia de Higini Anglès por el país en el que se había formado como musicólogo y en el que pudo establecer muchos contactos durante sus años de estudios- la que contó con la mayor proporción de representación extranjera en el Congreso: Curt Sachs, Egon Wellesz, los más jóvenes Curt Huber, Heinrich Besseler y un jovencísimo Manfred Bukofzer, entre otros, estuvieron todos ellos en Barcelona presentando personalmente sus comunicaciones.

A comienzos de agosto, y antes de comenzar el turno de contactos epistolares con los posibles comunicantes que debían intervenir en el Congreso, Higini Anglès ya tiene decidida su estructura organizada alrededor de los dos ámbitos de rigor: $1 /$ historia de la música y $2 /$ folklore, a los que nuestro musicólogo tiene la intención, como así se lo comunica a Edward j. Dent ${ }^{37}$, de añadir un 3/ dedicado al canto gregoriano:

«En 1930, en parlant avec Peter Wagner au sujet d'un futur Congrès de Musicologie à Barcelone, je lui avais suggéré la nécessité de faire entrer dans le projet une section de gregorianisme, pour tâcher d'obtenir un trait d'union entre les moines bénédictins et les musicologues et pour arriver, d'autre part, à unir les efforts des bénédictins allemands et belges avec les français. J'ai déjà parlé à ce sujet avec Dom Gajard, le successeur de Dom Mocquerau à Solesmes, et avec le RR.P. Abbé de Beuron.

37 ANGLÈS, (Barcelona, 1935), Correspondència del Congrés, Fons Higini Anglès Biblioteca de Catalunya $(\boldsymbol{E}-B b c)$. (ver pie de página $\left.\mathrm{N}^{\circ} 16\right)$.
Cette section ne serait donc pas difficile d'organiser et on pourrait le faire présider par Dom G. M Sunyol de Montserrat, actuellement professeur à Milan, ami de Solesmes et des allemands. Qu'en pensez-vous ?».

Dos son los objetivos fundamentales que mueven a Anglès a tomar su decisión de incorporar el canto gregoriano como materia específica de una de las secciones del Congreso, y estos objetivos se los expone claramente a su amigo el Padre Gregori M Sunyol ${ }^{38}$, en carta redactada tan sólo cuatro días después de la enviada a Dent en la que se invitaba al monje montserratino, entonces director de la Escuela de Música Sacra de Milán, a presidir el nuevo ámbito del Congreso. Tras informarle de la petición formulada a Dent de añadir una sección gregorianista en el encuentro, Anglès justifica esta incorporación con estas palabras:

«Amb aquesta Secció, els benedictins que assistissin al Congrés podrien posar-se en relació personal directa amb els musicòlegs, cosa que podria reportar fruits bonics en pro dels uns i dels altres. Ultra això, els benedictins alemanys entrarien definitivament en relació personal bona amb els de França. Com a President de la Secció li proposava jo el nom de vostè».

Es decir, si por un lado la presencia de clérigos especialistas en canto litúrgico -normalmente reticentes por principio a participar en foros internacionales de carácter científico- serviría para propiciar el diálogo y fomentar el intercambio fructífero de ideas, hasta entonces prácticamente inexistente, entre aquel grupo y la generalidad de la musicología universitaria, por otro lado y ya en el terreno del propio canto gregoriano una plataforma de este tipo favorecería igualmente la interacción entre las distintas tradiciones monásticas y las diferentes concepciones nacionales de cara, entre otras muchas cosas, a la urgente elaboración de un catálogo unificado, sistemático y detallado de manuscritos gregorianos de la Edad Media, tema éste que sería objeto exclusivo de una de las dos comunicaciones escritas por Higini Anglès, y leídas en este encuentro.

Y para dar solidez a su argumentación Anglès empleó gran cuidado en obtener la participación en el Congreso de Dom Joseph Gajard, maestro de coro de la Abadía de monjes benedictinos de Solesmes e ilustre discípulo de Dom André Mocquerau en las tareas de la renovación y revitalización del canto gregoriano. La visita de Gajard a Barcelona era un incentivo lo suficientemente poderoso para galvanizar interna-

38 ANGLÈS, (Barcelona, 1935), Correspondència del Congrés, Fons Higini Anglès Biblioteca de Catalunya $(\boldsymbol{E}-B b c)$. 
cionalmente el interés por el canto litúrgico y por ende para contribuir al éxito de aquellas jornadas. Por esto Anglès ${ }^{39}$ no puede ocultar su satisfacción al agradecer al monje benedictino la aceptación de su invitación, y en su breve discurso de clausura del encuentro ${ }^{40}$ el musicólogo catalán recalcó una vez más la importancia de habers incluido por primera vez aquella sección, hecho que esperaba iba a sentar precedente para futuros congresos de musicología:

" Les études de la musique du moyen âge exigent des relations bien étroites entre les bénédictins et grégorianistes avec les musicologues. Le premier essai a donné des bons fruits. C'est pour cela que je vous prie quand vous convoquez les futurs congrès de la SIM de ne pas oublier la section du grégorianisme scientifique. Comme résultat de cette section je peux vous annoncer que à la séance du jeudi, les bénédictins français, allemands et espagnols ont offert la collaboration pour préparer la catalogue des manuscrits grégoriens du IX au XIII siècle. Donc un des travaux immédiats de la SIM sera l'édition de ce catalogue ajoutant de cette manière les travaux des bénédictins aux travaux qu'on fait aux centres de catalogation à Bâle et à Berlin ».

A estos tres ámbitos previstos desde el principio vino finalmente a añadirse en el último momento, ya casi en vísperas de la celebración del Congreso, una 4/ sección dedicada a la música religiosa para órgano. La idea le fue sugerida a Anglès, según cuenta él mismo a Dent ${ }^{41}$ un mes antes de que se celebrara el Congreso, por el canónigo de Notre-Dame de Estrasburgo, Franz-Xavier Mathias, y debía contemplar el estudio del repertorio litúrgico para aquel instrumento en sus respectivas vertientes católica y luterana; de la primera debía cuidarse el propio Franz-Xavier Mathias mientras que la segunda iría a cargo de su colega organista en Estrasburgo, Théodore Gérold.

Tampoco no fue hasta el postrer momento que se introdujo un nuevo cambio en el organigrama de ámbitos, esta vez obligado por el excesivo número de comunicaciones recibidas en la Secretaría de la delegación catalana de la SIM. Las ponencias reunidas por Higini Anglès hasta comienzos

39 ANGLÈS, Correspondència del Congrés, Fons Higini Anglès Biblioteca de Catalunya $(\boldsymbol{E}-B b c)$.

40 ANGLÈS, 1936, [Discurso leído por Higini Anglès como clausura del Congreso conservado en 10 medios folios autógrafos], Documentació Congrés, Fons Higini Anglès Biblioteca de Catalunya $(\boldsymbol{E}-B b c)$.

41 ANGLÈS, 1936, Correspondència del Congrés, Fons Higini Anglès Biblioteca de Catalunya $(\boldsymbol{E}-\boldsymbol{B} b \boldsymbol{c})$. Carta inventariada entre las de destinatario no identificado pero cuyo contenido nos permite suponer que iba dirigida al presidente de la SIM. de marzo de 1936 llegaban a la cuarentena -según comenta Anglès $^{42}$ a Dent en la última de las cartas que ambos se intercambian antes de la celebración de las jornadas; y este cuantioso volumen aconsejaba subdividir la 1/ Sección, la dedicada a historia de la música, en dos subsecciones: a/ Historia antigua (en términos actuales desde la Edad Media hasta finales del barroco) y b/Historia moderna (desde el preclasicismo hasta la música contemporánea).

Así pues, el Congreso quedó definitivamente estructurado en cinco secciones: Historia antigua, Historia moderna, Folklore, Gregorianismo, Órgano. Estos ámbitos reunían las comunicaciones pertenecientes a sus respectivas áreas específicas y debían funcionar de forma simultánea -lo que suponía poder contar con cuatro salas o aulas independientes en el Institut d'Estudis Catalans- a lo largo de las mañanas de los cuatro días (del lunes, 20 de abril al jueves, 23 de abril) que duró el encuentro, puesto que el viernes los congresistas junto a los "festivalistas" (compositores, intérpretes y críticos inscritos en el Festival) debían ser todos trasladados en autocares desde el lugar de encuentro a las puertas del Palau de la Música al Monasterio de Montserrat en visita organizada que incluía un concierto a cargo de la Escolanía y los monjes de aquel Monasterio.

Cada una de las cinco secciones en activo prácticamente cada día contaba con la presencia de un presidente de mesa que coordinaba a los comunicantes allí convocados dándoles el turno de palabra y moderando el posible debate que pudiera surgir entre ellos. Cada mesa congregaba hasta un máximo de cinco comunicantes, los cuales disponían de quince a veinte minutos para hacer su exposición en alemán, francés, inglés, italiano o cualquiera de las lenguas del Estado español, aunque se encareciera por parte de la organización el uso del francés en el caso de comunicantes extranjeros. Ésta diversidad lingüística ya era un indicador del carácter restringido y de interés exclusivamente reservado a los propiamente "congresistas" que debieron tener las sesiones, aunque dada la repentina sobrepoblación internacional de profesionales de la música concentrada en aquel momento en Barcelona a causa del Festival, es lógico que muchos de ellos y especialmente reporteros y comentaristas de la prensa extranjera ${ }^{43}$, citados para cubrir los estrenos y conciertos del Festival, asistieran como oyentes a algunas

42 ANGLÈS, 1936: Ibid.

43 Fueron numerosos los medios de prensa internacionales que enviaron periodistas y comentaristas musicales a Barcelona con ocasión del Festival, que dieron a su vez información acerca del Congreso sobre todo en lo que a conciertos de música histórica se refiere pero también sobre sus sesiones académicas. Un ejemplo de ello es el artículo que le dedica Paul Stefan desde las páginas de la revista norteamericana Musical America. 
de las conferencias del Congreso. Lo que sí sabemos, gracias al testimonio de Joan Salvat, director entonces de la Revista Musical Catalana y autor del único resumen ${ }^{44}$ verdaderamente exhaustivo y pormenorizado de las sesiones del Congreso que publicó en aquella revista, es que el ámbito dedicado a Folklore fue el más concurrido por el público debido -señala el crítico- al carácter más accesible del contenido de sus ponencias y al aliciente de estar ilustradas algunas de ellas con ejemplos de cantos interpretados por músicos populares; y a los motivos expuestos por Salvat cabría añadir una razón incluso más decisiva de orden lingüístico, y es que en la sección de Folclore convergieron por su temática buena parte de las comunicaciones presentadas por los miembros de la Delegación española de la SIM, que en su mayoría fueron los mismos coordinadores regionales o por comunidad que eligiera Higini Anglès, lo que significa que en esta sección predominara el castellano como lengua comunicativa, cosa que sin duda había de favorecer la asistencia de público en este ámbito.

De todas maneras, Higini Anglès quiso compensar el tono docto, y por lo tanto casi siempre minoritario, de las exposiciones científicas en las sesiones con dos conferenciasaudición de carácter más divulgativo que se celebraron en el Salón de actos de la Reial Acadèmia de Medicina, en el edificio situado enfrente de la Casa de Convalecencia donde tiene su sede el Institut d'Estudis Catalans. La primera de ellas ${ }^{45}$ la pronunció Dom Joseph Gajard sobre la interpretación del canto gregoriano, con ejemplos cantados por Gajard, Dom Maur Sablayrolles y el padre Gregori $\mathrm{M}^{\mathrm{a}}$ Sunyol (ambos, igualmente ponentes en la sección Gregorianismo); y la segunda ${ }^{46}$ la dió Curt Sachs y versó en torno a los problemas de la interpretación de la polifonía medieval, conferencia esta vez ilustrada con discos en 78 revoluciones de su extensa colección fonográfica Anthologie sonore que había empezado a publicarse en París en 1933.

44 SALVAT, 1936. Nos referimos al artículo de quince páginas, firmado con las iniciales J. S., que Joan Salvat dedica al Congreso desde las páginas de la Revista Musical Catalana.

45 En la misma carta de Anglès a Joseph Gajard (cit. en 36) el musicólogo catalán le proponía al Maestro de coro de Solesmes hacer esta conferencia, que tuvo lugar en el Salón de actos de la Real Academia de Medicina, el martes 21 de abril a las 12.30 del mediodía.

46 ANGLÈS, (Barcelona,1936), Correspondència del Congrés, Fons Higini Anglès Biblioteca de Catalunya $(\boldsymbol{E}-B b c)$. De esta carta puede inferirse que en este caso fue Curt Sachs quien propuso a Anglès dar esta conferencia-audición. Curt Sachs aprovechó su estancia en Barcelona con motivo del Congreso para promover su nueva colección discográfica ya que también pronunció -fuera del marco del Congreso- una conferencia similar en el Hotel Ritz de Barcelona, esta vez organizada por Discòfils Associació Pro música, un activa asociación de aficionados al nuevo soporte musical que se había creado hacía muy poco en Barcelona.
C/ Las comunicaciones presentadas

Uno de los principales problemas que surgen a la hora de afrontar la investigación crítica acerca de los contenidos del Congreso de musicología de 1936 en Barcelona es establecer -lógicamente, antes de que se pueda emprender el análisis y comentario de las comunicaciones allí presentadas- el número de las que allí fueron efectivamente leídas, y a continuación, el índice de las actualmente conservadas por escrito en el Fondo Higini Anglès. Porque, para empezar, existe una notable discrepancia entre las 76 comunicaciones que aparecen anunciadas en el programa oficial del Congreso $^{47}$ y el listado mecanografiado, confeccionado poco antes de la celebración de las jornadas, de 55 comunicaciones (título de la comunicación y autor) que figura entre los papeles ${ }^{48}$ de Anglès. Sin embargo, tampoco podemos dar por definitivo este listado ya que existen ponencias entre la totalidad de las conservadas (34) que no aparecen allí citadas y además hay otras que, sin existir copia de ellas, sabemos que se presentaron en el Congreso por reseñas de prensa ${ }^{49}$ publi- $^{-}$ cadas con posterioridad al encuentro. Así pues, el estudio de toda la documentación -hasta ahora inventariada- sobre el III Congreso Internacional de Musicología que se guarda en la Biblioteca Nacional de Catalunya, nos ha permitido elaborar el siguiente listado estructurado por ámbitos de las comunicaciones que realmente allí se presentaron , en corrección de las anunciadas en el programa oficial del Congreso. En este listado presentado por orden alfabético de autores, se indica primero el nombre del comunicante con su ciudad de

47 Congrés de la Societat Internacional de Musicologia de Barcelona. Programa de les sessions i festes que es celebraran del 18 al 25 d'abril. (Impremta Casa de la Caritat). Publicación de 47 páginas en la que no sólo aparece la listado de comunicaciones y sus autores, por ámbitos y horario de las sesiones, sino también la programación exhaustiva de todos y cada uno de los conciertos de música histórica organizados directamente por el Congreso, así como el comentario de las obras y los textos de las piezas cantadas.

48 Este listado mecanografiado de comunicaciones hecho con papel y membrete del Congreso, aunque no está datado, debió hacerse con posterioridad a la publicación del Programa oficial y en fecha muy cercana a la celebración, ya que lo acompañan algunas correcciones efectuadas sobre aquel programa; por este documento sabemos, por ejemplo, que la sección Gregorianismo no se inauguró el lunes -según lo programado- sino un día después, el martes, día 21.

49 Amédée Gastoué, especialista en canto litúrgico y participante en la sección de Gregorianismo, publica en la revista parisiense Le Noël, Revue Hebdomadaire pour les jeunes filles. Maisson de la Bonne Presse, en el mes de octubre de 1936, un resumen de las sesiones del Congreso, y por esta reseña sabemos que -en contra de lo que consta en el Programa oficial - las comunicaciones presentadas en la sección de Órgano no pudieron concentrarse debido a su número en un solo día, como allí aparecía anunciado, sino que debieron exponerse a lo largo de dos días consecutivos. 
procedencia, después el título de la comunicación, y en tercer lugar se marca con un asterisco aquellas comunicaciones del Congreso que se conservan actualmente en el Fondo Higini Anglès ya sea en forma manuscrita o mecanografiada.

\section{Sección Historia antigua}

-Anglès, Higini (Barcelona): La musique de la cour pontificale d'Avignon du XIV siècle, en Catalogne*

-Besseler, Heinrich (Heildelberg): Die Anfänge der musikalischen Neuzeit

-Donostia, P. José Antonio (Lecaroz, Navarra): La música de Juan Anchieta, siglos XV-XVI*

-Einstein, Alfred (Viena): The change of tempo in the Italian madrigal *

-Engel, Hans (Königsberg): Soziologische Betrachtung des Madrigales

-Freitas Branco, Luiz de (Lisboa): Musique portugaise ancienne dans les archives étrangères *

-Geordiades, Thra G. (Atenas): Untersuchungen zur englischen Mehrstimmigkeit bis Dunstable *

-Gérold, Théodor (Estrasburgo): La musique à Strasbourg dans la première moitíe du XVI siècle

-Jeppesen, Knud (Copenhaguen): Eine Musiktheoretische Korrespondenz des früheren Cinquecento

-Liuzzi, Fernando (Roma): Note sul manoscritto vaticanorossiano 215 (Lirica musicale italiana del sec. XIV) *

-Pujol, Emili (París): La transcription de la tablature pour vihuela d'après la technique de l'instrument *

-Ricart i Matas, Josep (Barcelona): Les instruments musicaux dans l'iconographie hispànique du moyen âge

-Ripollès, Vicenç (València): Los ministriles de los siglos XVI-XVIII en la catedral de Valencia

-Sachs, Curt (París): Vers une préhistoire musicale

-Subirà, José (Madrid): Un fondo desconocido de música para guitarra

-Ursprung, Otto (Munich): Spanische Musik der Vor-Reservata um 1500, und der Früh-Reservata

\section{Sección Historia moderna}

-Cherbuliez, Antoine E. (Zurich): La Sarabande, la Chaconne, la Passacaille et la Folia dans l'oeuvre de J.S. Bach

-Hansdchin, Jacques (Basilea): La notion de "qualité" dans la psychologie du son *

-Haraszti, Emile (París): Les problèmes de l'art de Liszt et son double aspect $*$

-Istel, Edgard (Madrid): Work and Personality of Felipe Pedrell (1841-1922) *
-Kastner, Santiago (Lisboa): Le style musical du Père Manoel Rodriguez Coelho*

-Kókai, Rudolf (Budapest): Die Stileigentümlichkeiten der Kunst von Franz Liszt dargestellt am musikalischen Material seines Skizzenbuches Ms, N6, Liszt-Museum, Weimar*

-Liuzzi, Fernando (Roma): Un nuovo schedario di bibliografia musicale romana presso l'Istituto di Studi Ro$\operatorname{mani} *$

-Luin, Elisabet J. (Roma): L'importanza delle "Stabat Mater" di Pergolesi nei Paesi Nordici, prima della Diffusione della Mathäus-Passion di Giov. Seb. Bach*

-Masson, Paul Marie (Paris): Le recueil madrilène des "Canciones franceses para todos los instrumentos". Vers 1700

-Mooser, Aloys (Ginebra): Un musicien espagnol en Russie à la fin du XVIII siècle: contribution à la biographie de Vicenç Martin i Soler et à la bibliographie de son oeuvre

-Pujol, P.David (Montserrat): Un llibre manuscrit amb dotze misses de Pierre Manchicourt, mestre de capella de Felip II

-Pulikowski, Juljan von (Varsovia): Probleme und Aufgaben der Musikgeschichte*

-Subirà, José (Madrid): La música instrumental al servicio de las obras dramáticas declamades

\section{Sección Folklore}

-Barberà, josep (Barcelona): Supervivències gregues en la cançó popular catalana*

-Bukofzer, Manfred (Basilea): Zur Erkclärung des "Lobetanz"durch die schweizerische Volmusik*

-Bukofzer, Manfred (Basilea): Zur Frage der Blasquinte in den exotischen Tonsystem *

-Campo, Conrado del (Madrid): Sobre armonización del canto popular *

-Cherbuliez, Antoine E. (Zuric): La canción popular en la Suiza Rética

-Coirault, Patrice (Paris): Quelques exemples de la parenté qui montrent des timbres populaires aux XVIIe et XVIIIe siècles avex certaines de nos mélodies folkloriques

-Fara, Giulio (Nápoles): Etnofonia e civiltà mediterranea (le basi della Storia della musica)

-Gibert, Vicenç $\mathbf{M}^{\mathbf{a}}$ de (Barcelona): Les melodies de les cançons romanesques a Catalunya*

-Gil, Bonifacio (Extramadura): 1/ Extremadura y la posible regionalización de su música popular. 2/ La tradición en la canción extremeña.* 
-Huber, Kurt (Munic): Zur Typologie des Volkslieds im Mittel-und Westeuropäischen Raum

-José, Antonio (Burgos): La canción popular burgalesa*

-Lima, Emirto de (Barranquilla, Colombia): Las flautas indígenes *

-Merlier, Melpo (Atenes): Création à Athènes, d'archives musicales de folklore *

-Otaño, Nemesio (Azcoitia, Guipuzcoa): Notas sobre el folklore gallego

-Pujol, Francesc (Barcelona): Ritme i metrificació de les cançons populars catalanes *

-Samper, Baltasar (Barcelona) : El cant de les cançons de treballada a Mallorca*

-Tiersot, Julien (París): Les chansons populaires de la France et de la Catalogne*

-Torner, Eduardo M. (Madrid) : Los ritmos en la música popular castellana

-Turina, Joaquín (Madrid): El canto popular andaluz *

\section{Sección Gregorianismo}

-Anglès, Higini (Barcelona): Necessité d'un catalogue detaillé des manuscrits grégoriens dun moyen-âge*

-Fellerer, Karl Gustav (Fribourg, Suiza): Modus und Melodiemodell $*$

-Franquesa, Josep (Sabadell): Darreres troballes sobre el cant visigòtic

-Gajard, Dom. Joseph (Solesmes): La restitution mélodique du chant grégorien

-Gastoué, Amadée (París): Les récitatifs litúrgiques du còdex espagnol Res.F.967 de la bibliothèque du Conservatoire National de Musique à Paris *

-Johner, P.Dominicus (Beuron, Colonia): Der Dialog im liturgischen Gesang *

-Kosch, Franz (Viena): Zum Choral der Franciscaner im XIII. Jahrhundert

-Sablayrolles, Dom. Maur (En-Calcat, Francia): Un regard sur mon Iter Hispanicum

-Sunyol, P. Gregori Ma (Montserrat-Milà): La modalitat del cant litúrgic llatí

-Sunyol, P. Gregori $\mathbf{M}^{\mathbf{a}}$ (Montserrat-Milà): La modalitat del cant litúrgic llatí

-Van, Guillaume de (París): Les neumes d'ornement dans le chant grégorien *

-Wellesz, Egon (Viena): Stand der bysantinischen Forschung

\section{Sección Órgano}

-Boëllmann, Marie Louise (París): Le pénétration en France de la musique d'orgue de J.S. Bach au XIX siècle
-Dufourg, $\mathbf{N}$ (París): Le maître franco-espagnol Aristide Cavaillé-Coll (1811-1899) et l'évolution de la musique d'orgue en France

-Gérold, Théodor (Strasbourg): La section d'orgue au Congrès de la SIM à Vienne 1909, point de départ du mouvement organal actuel

-Le Comte Bérenger de Miramon (Neully-sur Seine): Les plus récentes entreprises de la Societé Française des "Amis de l'orgue"

-Mathias, Franz Xaver (Strasbourg): La Societé Internationale d'orgue, son activité aux Congrès de Budapest (1930), Strasbourg (1932) et Luxemburg (1934)

-Mockers, F. (París): La famille franco-suisse Mockers, complétant en France l'oeuvre organale d'Aristide Cavaillé-Coll, en continuant celle de Jean Silbermann (1712-1783)

-Otaño, P. Nemesio (Azcoitia, Guipuzcoa): La organería y los órganos del país vasco

-Thomàs, Joan $\mathbf{M}^{\mathbf{a}}$ (Palma de Mallorca): Jordi Bosch, le plus grand facteur espagnol d'orgues du XVIIIème siècle*

-Walter, N. (Villefranche, Francia): L'évolution de la musique d'orgue française au XIX siècle sous l'influence d ela musique d'orgue de J.S. Bach

Finalizado el Congreso, Higini Anglès se puso inmediatamente a recabar de los ponentes que todavía no lo habían hecho la entrega de las comunicaciones que, todas ellas reunidas, deberían constituir el libro de las Actas del encuentro. Se fijó el 15 de junio como data límite de recepción de los trabajos que faltaban aunque sabemos por carta ${ }^{50}$ enviada a Dent que a pocos días de finalización del plazo establecido el musicólogo catalán todavía estaba recibiendo comunicaciones; pero es a mediados de julio, por carta del musicólogo dirigida a Rafael Patxot ${ }^{51}$, cuando conocemos que por aquellas fechas Anglès ya disponía prácticamente de todas las comunicaciones así como de un presupuesto para la edición de las Actas expedido por la Impremta Casa de la Caritat -el mismo taller tipográfico en el que se había imprimido el Programa del Congreso- con las características del libro:

50 ANGLÈS, (Barcelona, 1936), Correspondència del Congrés, Fons Higini Anglès Biblioteca de Catalunya $(\boldsymbol{E}-B b c)$. En esta carta, además, Anglès comunica al Presidente de la SIM la constitución de un Consejo de redacción para la supervisión de las comunicaciones de cara a su inminente publicación, que estaría integrado por Paul Marie Masson, Egon Wellesz y el propio musicólogo catalán.

51 ANGLÈS, (Barcelona, 1936), Correspondència del Congrés, Fons Higini Anglès Biblioteca de Catalunya $(\boldsymbol{E}-B b c)$. (carta cit. 21). 
«Es preveu un volum en octau, de 42 ratlles per pàgina i 76 lletres per ratlla. Se suposa que el volum tingui 480 pàgines, 150 planes amb exemples musicals -corresponents majoritàriament a la secció de folklore, la secció amb més èxit del congrés- i una separata de 16 pàgines amb el resum del congrés en castellà, català i idioma estranger: francès?. El cost total de 500 exemplars previstos ascendeix a 10.780 pts»

No obstante, al cabo de tan sólo dos semanas del envío de esta carta estallaba la Guerra Civil y el proyecto quedó para siempre truncado.

\section{D/ Los conciertos del Congreso}

Independientemente del interés del contenido de las 69 comunicaciones científicas que se expusieron en el Institut d'Estudis Catalans y del hecho de que en Barcelona se dieran cita algunos de los musicólogos que han marcado después las principales directrices del desarrollo de aquella disciplina en el siglo XX, como Manfred Bukofser, Heinrich Besseler, Knud Jeppesen, Alfred Einstein ${ }^{52}$ o Egon Wellesz, entre otros, lo que hizo de aquel encuentro un acontecimiento extraordinario -verdaderamente insólito en el entorno cerrado habitual en que se mueve la musicología -fue su poder de incidencia en el tejido de la vida cultural de una ciudad gracias a la serie de conciertos históricos que se celebraron en Barcelona, en perfecta coordinación con la programación de conciertos del Festival de Música Contemporánea. El soporte institucional con que en el aspecto musical contó el Congreso, la sensibilidad que los responsables políticos demostraron ya desde el solemne acto de apertura del Festival y el Congreso en el Palau de la Generalitat con su presidente, Lluís Companys queriendo dar la bienvenida en persona a los invitados, y que continuaron después en el seguimiento de los actos por parte del propio Conseller de Cultura, Ventura Gassol $^{53}$, fue un exponente más de la movilización general producida en la sociedad catalana con motivo de un encuentro científico que venía a legitimar el creciente interés que un considerable sector de intérpretes y aficionados barceloneses sentían por la música antigua, es decir aquella anterior a la imposición de estándares fijados por la música de repertorio. De esta manera entidades como Ars Musicae, el Orfeó Català, la Associació de Música Antiga o el Club de

52 Este musicólogo e historiador al final no vino a Barcelona pero envió de todas formas su ponencia, que fue leída en el encuentro.

53 El responsable de Cultura de la Generalitat de Catalunya recibió en su despacho, el sábado día 25 de abril, una comisión de delegados del Congreso: Paul Marie Masson, Knud Jepessen i Higini Anglès, que quisieron regraciar a las autoridades catalanas por todas las atenciones recibidas. (Diario La Vanguardia, 26-4-1936).
Futbol Junior ${ }^{54}$ se sumaron inmediatamente al proyecto de Higini Anglès con quién mantuvieron un estrecho contacto en la concreción de los programas de sus conciertos. Se programaron en total cinco conciertos: el protagonizado por el Orfeó Català, en el Palau de la Música, con un ambicioso programa "de música hispánica de los siglos XIII al XVII y la escuela coral moderna catalana”; el de Ars Musicae, en el Arxiu de la Ciutat (Casa de 1'Ardiaca) dedicado preferentemente a música instrumental hispana de los siglos XV, XVI y XVII; el organizado por la Associació de Música Antiga en el Casal del Metge con un concierto de música para vihuela a cargo del guitarrista Emili Pujol y la soprano Conxita Badia; el de la compañía de aficionados Junior F.C. con la representación en el Teatro Tívoli de la ópera Una cosa rara, de Vicenç Martí i Soler; el celebrado en el Monasterio de Montserrat a cargo de los monjes y escolanía ("Concert de polifonia religiosa dels segles XII-XVII); y por último, además de otro concierto en la residencia privada en Pedralbes del empresario Josep $\mathbf{M}^{\mathrm{a}}$ Roviralta, el festival de danzas populares celebrado en el Poble Espanyol de Montjuic.

$\mathrm{Si}$ admitimos que la conquista de la contemporaneidad en la historia de la recepción musical del siglo XX viene dada por la apertura del público a otros estilos de música distintos a los perpetuados por la tiranía de la música de repertorio, podríamos concluir que la coincidencia de los conciertos históricos del Congreso y los de música contemporánea del Festival y su reivindicación a favor precisamente de unos estilos que forzando a mirar respectivamente hacia atrás o hacia adelante en el tiempo ponían en crisis el modelo mismo de repertorio, hizo que Barcelona durante aquella semana del mes de abril de 1936 se situara en el centro mismo de aquella contemporaneidad europea que iba a ser muy pronto brutalmente arrasada por otros tipos bien distintos y violentos de regresión histórica.

\section{Bibliografía}

Anglès, Higini, [Carta manuscrita de Higini Anglès al Padre José Antonio Donostia], (carta sin datar).

Anglès, Higini, [Carta autógrafa de Higini Anglès a Joseph Gajard], (carta sin datar).

Anglès, Higini, [Carta manuscrita de Higini Anglès a Joaquim Folch i Torres] (Barcelona, sin datar).

54 Esta entidad deportiva creada en Barcelona en 1917 e integrada en su mayor parte por socios que ejercían profesiones liberales: abogados, médicos, ingenieros, etc., compaginaban su afición deportiva con otras de tipo cultural, como la de montar anualmente la representación de una ópera que no se hubiera ejecutado nunca en España. 
Anglès, Higini., [Carta mecanografiada de Higini Anglès a Edward J. Dent], (Barcelona, 21-06-1935).

Anglès, Higini, [Carta mecanografiada de Higini Anglès a Edward J. Dent], (Barcelona, 02-08-1935).

Anglès, Higini, [Carta mecanografiada de Higini Anglès a Manuel de Falla] (04-08-1935).

Anglès, Higini, [Carta autógrafa de Higini Anglès a Gregori M. Sunyol], (Barcelona, 06-08-1935).

Anglès, Higini, [Carta mecanografiada de Higini Anglès a Manuel de Falla] (06-08-1935).

Anglès, Higini, [Carta mecanografiada de Higini Anglès a John Brande Trend], (Barcelona, 18-11-1935).

Anglès, Higini, [Carta mecanografiada de Higini Anglès a Edward J. Dent] (Barcelona, 08-03-1936).

Anglès, Higini, [Carta de Higini Anglès a Curt Sachs], (Barcelona, 30-03-1936).

Anglès, Higini, [Carta de Higini Anglès a Edward J. Dent], (Barcelona, 08-06-1936).

Anglès, Higini, [Carta de Higini Anglès a Rafael Patxot], (Barcelona, 10-07-1936).

Anglès, Higini, [Discurso leído por Higini Anglès como clausura del Congreso conservado en 10 medios folios autógrafos], (Barcelona, 1936).

Bal y Gay, Jesús, [Carta autógrafa de Jesús Bal i Gay a Higini Anglès] (Madrid, 02-09-1935).

Chailley, Jacques, [Carta autógrafa de Jaques Chailley a Higini Anglès] (1936).

Congrés de la Societat Internacional de Musicologia de Barcelona. Programa de les sessions i festes que es celebraran del 18 al 25 d'abril. Barcelona, Impremta Casa de la Caritat.

Del Campo, Conrado, [Carta autógrafa de Conrado del Campo a Higini Anglès] (20-02-1936).

Dent, Edward J., [Carta mecanografiada de Edward J. Dent a Higini Anglès] (Cambridge, 27-06-1935).

Dent, Edward J., [Carta mecanografiada de Edward J. Dent a Joan Llongueras], (Cambridge, 24-08-1935).
Dent, Edward J, [Prólogo del programa de mano del Festival], Societat Internacional per la Música Contemporània. XIV Festival. Barcelona 18-25 d'abril. Barcelona. Oliva de Vilanova [238 p.].

Falla, Manuel de, [Carta manuscrita de Manuel de Falla a Higini Anglès], (Granada, 07-02-1936).

Fernández-Arbós, Enrique, [Carta mecanografiada de Enrique F. Arbós a Higini Anglès] (Madrid, 30-08-1935).

Gil, Bonifacio, [Carta autògrafa de Bonifacio Gil a Higini Anglès] (Badajoz, sin data).

Lamote, Joan, [Carta manuscrita de Joan Lamote dirigida a Higini Anglès y enviada el desde su alojamiento en el Esplanade Hotel de Praga], (Praga, 02-09-1935).

Lliurat, Frederic, "III Congrés de Musicologia. XIV Festival de Música Contemporània”, La Veu de Catalunya (Barcelona, 24-04-1936).

López-Chavarri, Eduardo, [Carta manuscrita de Eduardo López-Chávarri a Higini Anglès] (Valencia, 03-031936).

Salazar, Adolfo, [Carta manuscrita de Adolfo Salazar a Higini Anglès], (Madrid, 14-12-1935).

Salazar, Adolfo, "La XIV reunió de la Sociedad Internacional de la Música Contemporánea en Barcelona", El Sol (Madrid, 24-04-1936).

Salvat, Joan (J.S.), "El III Congrés de la Societat Internacional de Musicologia a Barcelona 1936", Revista Musical Catalana, Maig 1936, [15 páginas].

Samper, Baltasar, "Resum del Congrés y del Festival", $L a$ Publicitat, (Barcelona, 25-04-1936).

Stefan, Paul, "Contemporary Music Society meets in Spain", Musical America, (25-05-1936).

Subirà, Josep, [Carta mecanografiada de Josep Subirà a Pau Casals] (Madrid, 16-02-1936).

Subirà, Josep, "El Congreso Internacional de Musicología", El Socialista, (Madrid, 03-05-1936).

Turina, Joaquín, [Carta autógrafa de Joaquín Turina a Higini Anglès] (carta no datada).
Recibido: 24.04 .2014

Aceptado: 02.10.2015 